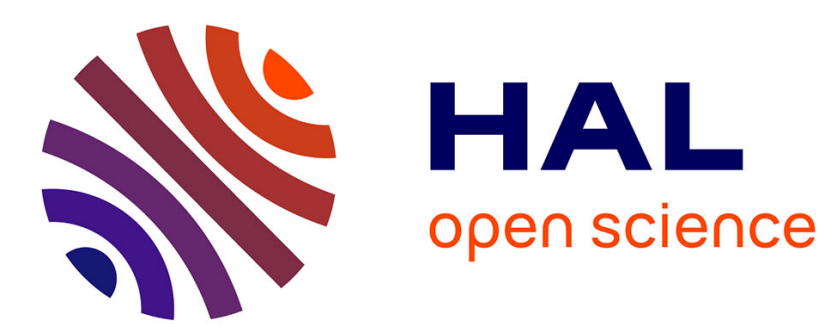

\title{
Investigation of the forming limit strains at fracture of AA5086 sheets using an in-plane biaxial tensile test
}

Xiao Song, Lionel Leotoing, Dominique Guines, Eric Ragneau

\section{To cite this version:}

Xiao Song, Lionel Leotoing, Dominique Guines, Eric Ragneau. Investigation of the forming limit strains at fracture of AA5086 sheets using an in-plane biaxial tensile test. Engineering Fracture Mechanics, 2016, 163, pp.130-140. 10.1016/j.engfracmech.2016.07.007 . hal-01359364

\section{HAL Id: hal-01359364 https://hal.science/hal-01359364}

Submitted on 7 Sep 2016

HAL is a multi-disciplinary open access archive for the deposit and dissemination of scientific research documents, whether they are published or not. The documents may come from teaching and research institutions in France or abroad, or from public or private research centers.
L'archive ouverte pluridisciplinaire HAL, est destinée au dépôt et à la diffusion de documents scientifiques de niveau recherche, publiés ou non, émanant des établissements d'enseignement et de recherche français ou étrangers, des laboratoires publics ou privés. 


\title{
Investigation of the forming limit strains at fracture of AA5086 sheets using an in-plane biaxial tensile test
}

\author{
X. Song ${ }^{\mathrm{a}}$, L. Leotoing ${ }^{\mathrm{a}, *}$, D. Guines ${ }^{\mathrm{a}}$, E. Ragneau ${ }^{\mathrm{a}}$ \\ ${ }^{a}$ Université Européenne de Bretagne, France, INSA-LGCGM-EA 3913, 20 Av. des \\ Buttes de Coësmes, CS 70839, 35708 Rennes Cedex 7, France
}

\begin{abstract}
An in-plane biaxial tensile test with a dedicated cruciform specimen is performed to determine the forming limit strains at fracture for aluminium alloy 5086. A method based on the evolution of strain in the central area of the specimen and the observation of the macroscopic image of specimen surface is proposed to identify the onset of fracture and the forming limit strains at this moment. The forming limit strains at fracture are determined under different strain paths provided by the two independent axes of the experimental device. Finite element simulations are performed to determine and compare numerical forming limit strains with three ductile fracture criteria (Cockroft and Latham, Brozzo and Ayada). The critical damage values of the criteria are determined by the experimental results under different strain paths.
\end{abstract}

Keywords: In-plane biaxial tensile test, Cruciform specimen, Forming Limit Curve at fracture, Ductile fracture criterion

\section{Introduction}

Necking is an undesirable surface defect in components made from sheet metals, so limits in sheet metal forming are more often controlled by localized necking rather than fracture [1]. However, under strain paths near balanced biaxial stretching or for some specific circumstances (e.g. deep drawn and stretched parts with complex geometries and high strain gradients) ductile

\footnotetext{
*Corresponding author

Email addresses: xiao.song@insa-rennes.fr (X. Song), lionel.leotoing@insa-rennes.fr (L. Leotoing), dominique.guines@insa-rennes.fr (D. Guines), eric.ragneau@insa-rennes.fr (E. Ragneau)
} 
fracture can be induced before the onset of localized necking. Besides, in case of materials with low ductility, fracture can often occur without any obvious necking phenomenon $[2,3]$. In that case, the limit strains controlled by fracture rather than the limit strains controlled by necking characterize the formability.

Figure 1 shows the schematic diagram of the forming limit curve at necking (FLCN) and forming limit curve at fracture (FLCF). For a given initial strain path, after the onset of strain localization, the material forms a necking and continues to deform under an almost plane-strain path up to fracture. For describing the forming limits by fracture under different strain paths, the traditional FLCN is inapplicable and the FLCF should be employed [4]. If

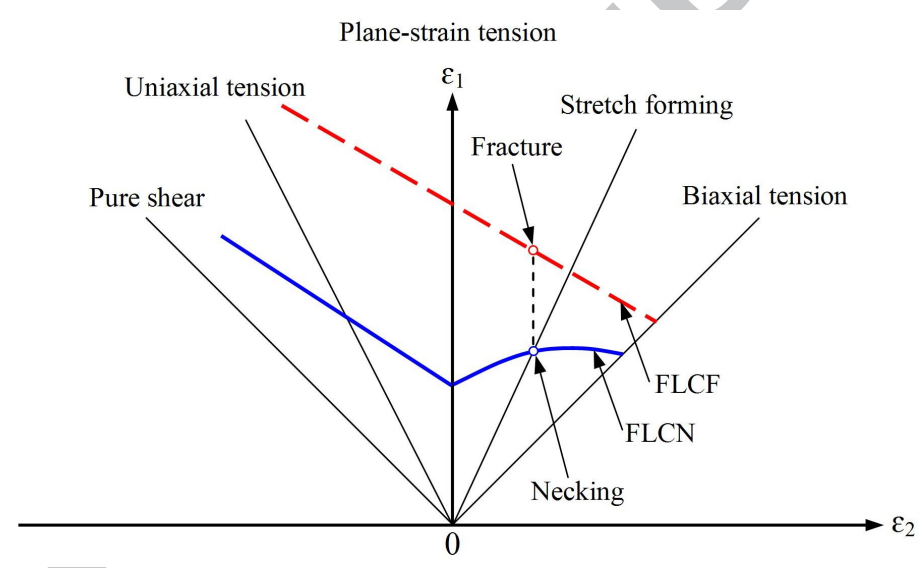

Figure 1: Schematic diagram of the FLCN and FLCF

necking appears before fracture, the plastic instability induces a fast thinning down of the sheet and then fracture. Classically, FLCF have been defined by a curve parallel to the FLCN but this representation is very simplistic and not appropriate to describe the actual limits of materials. Recently, the representation of FLCF was revisited in order to characterize the formability gain in some innovative processes, like the single point incremental forming (SPIF) process. For SPIF, greater deformability can be achieved than for traditional sheet metal forming processes. The onset of necking is delayed and the forming of the part fails by fracture. It is shown that the forming limit strains at fracture under different strain paths can be fitted by a straight line which is called Fracture Forming Limit line (FFL) [5, 6]. This concept was also adopted by the recent study of Isik et al. [7]. 
Many experimental methods have been used to obtain the FLCF. Isik et al. [7] have used several conventional sheet tests (tensile test, bulge test (circular and elliptical), Nakazima test and hemispherical dome test) to produce various strain paths to construct the FLCF of an aluminium AA1050H111. The forming limit strains at fracture can be fitted by a straight line. Moreover, the FLCF of the aluminium AA1050-H111 was also determined by the SPIF of truncated conical and pyramidal parts. The forming limit strains at fracture produced by SPIF can also be fitted by a line which is in excellent agreement with the one obtained from the conventional sheet formability tests. A similar approach was also adopted to plot the FLCF of the AISI304L stainless [8]. All these methods to plot the FLCF require many sheet tests and various geometrical specifications to produce the strain paths from equibiaxial to uniaxial tension. Using the biaxial tensile testing with cruciform specimens to determine the FLCF could be an interesting alternative to overcome some drawbacks of the conventional methods. Firstly, the biaxial test with a cruciform specimen is frictionless and the results are not influenced by bending. Secondly, the strain path during the test can be directly controlled by the motion of four independent actuators, which is sufficient to cover the whole forming limit diagram under linear $[9,10]$ and non linear [11] strain paths, with the same shape of cruciform specimen.

Failure in metalworking usually occurs as ductile fracture, rarely as brittle fracture [12]. Failure can be distinguished in two broader categories depending on the scale of interest of the material: microscopic or macroscopic [13]. The experimental determination of the FLCF is a time consuming process and requires specific equipments that may not always be available, while the numerical simulation method with ductile fracture criteria can be very efficient to predict the forming limits at fracture [14]. Physical observations and micromechanical analyses have led to the development of a number of phenomenological or micro/meso-mechanical motivated ductile fracture criteria. These criteria are classified into coupled (which incorporate damage accumulation into the constitutive equations) and uncoupled (which neglect effects of damage) categories [15]. The coupled ductile fracture criteria are based on micro-damage mechanics built upon the macroscopic yield surface for porous materials [16], or based on continuum damage mechanics [17]. The uncoupled ductile criteria are formulated empirically or semi-empirically with the general function $f$ in terms of certain macroscopic variables such as the equivalent plastic strain, tensile stress or hydrostatic stress, which are relevant to 
fracture initiation and propagation, as follows:

$$
\int_{0}^{\bar{\varepsilon}_{f}} f d \bar{\varepsilon}_{p}=C
$$

where $\bar{\varepsilon}_{f}$ and $\bar{\varepsilon}_{p}$ are respectively the equivalent strain at fracture and the equivalent plastic strain, $\mathrm{C}$ is the critical value for fracture. The fracture is assumed to occur when the internal damage reaches a critical value and results in a sudden loss of load carrying capability of the structure [18, 19]. The utilization of the uncoupled ductile criteria does not account for the progressive deterioration of the material, which is easier to implement and to calibrate than microscopic failure criterion. Moreover, it can provide good estimates of fracture loci in the principal strain space. Various ductile fracture criteria have been proposed and can be used to predict both the fracture initiation sites and the forming limits at fracture. Clift et al. [20] have reviewed commonly used ductile fracture criteria and predicted the fracture initiation for three metalforming operations. The results show that only the fracture criterion with a critical value of generalized plastic work per unit volume can successfully predict the fracture initiation sites. Takuda et al. [21] have compared four ductile fracture criteria (Cockroft and Latham, Brozzo, Oyane, Clift) to predict the forming limits for the axisymmetric deep drawing of various aluminium alloys (AA1100, AA2024 and AA5052) and mild steel sheet (SPCC). The results showed that various fracture initiations, with or without localized necking, are successfully predicted with Clift criterion. Mishra et al. [22] have also used four fracture criteria (Cockroft and Latham, Brozzo, Ayada, Rice and Tracey) to predict the onset of fracture in bending of DP980 steel sheet. The critical values of the criteria were identified by uniaxial tensile test. It is concluded that fracture in bending can be fairly well predicted by using either Rice and Tracey criterion or Ayada criterion.

Many researchers have adopted these ductile fracture criteria to build FLCF. Ozturk et al. [14] have used several criteria to predict the FLCF for AKDQ steel sheets. The predictions of limit strains at fracture for the left hand side of the FLCF are quite successful, while they are not precise for the right hand side. Takuda et al. [3] have used Oyane ductile fracture criterion to predict the FLCF for biaxial stretching of aluminium alloy sheets (AA1100 and AA5182). Material constants for the criterion are obtained from the fracture strains measured in the biaxial stretching test. By considering strain paths from uniaxial tension to balanced biaxial stretching, the FLCFs were 
approximately linear and can be successfully predicted by the fracture criterion. However, the FLCF of AA6111 measured by Jain et al. [23] had a rather complex shape approaching the FLCN towards the equibiaxial strain paths. The results showed that the various ductile fracture criteria with the integrated form could not completely predict the shape of the experimental FLCF, while the maximum shear stress criterion by Tresca predicts reasonably well the fracture limits from uniaxial to quasi-equibiaxial strain paths. To improve the predictions, an empirical ductile fracture criterion combining Cockroft and Latham criterion with the maximum shear stress criterion was proposed by Han et al. [4].

The aim of this study is twofold. The first objective is to show that the in-plane biaxial tensile test associated with a single type of cruciform specimen permits to investigate the forming limit strains at fracture under a wide range of strain paths. The experimental procedure and results are summarized in the following section. The second objective is to discuss the validity of classical ductile fracture criteria to predict the onset of fracture for aluminium alloy 5086 in finite element simulation of the in-plane biaxial tensile test. The last section is dedicated to this discussion.

\section{Experimental procedure and results}

\subsection{Cruciform specimen design and experimental device}

To carry out in-plane biaxial tensile tests, the design of the cruciform specimen remains the main difficulty to overcome. Various shapes of cruciform specimen have been proposed, depending on the mechanical behaviour to be characterized : yield locus, hardening model identification, determination of FLCN. Recently, a new standardized cruciform shape with seven slits in each arm has been proposed by the International Organization for Standardization (ISO) [24]. This standard specifies the testing method for measuring the biaxial stress-strain curves of sheet metals subject to biaxial tension at an arbitrary stress ratio. The measured biaxial stress-strain curves are used to determine contours of plastic work of the sheet samples. This standard is based on the research work of Kuwabara et al. [25]. Unfortunately, this shape cannot be used for investigating the forming limit strains at fracture since the strain level measured in the central zone is very low, fracture systematically appears in the arms. 
As shown in Figure 2, a dedicated cruciform specimen for obtaining large strains in the center was proposed by the authors [10] to plot FLCN. This geometry permits a direct control of the strain path in the fracture zone thanks to the control of the displacements of four independent actuators acting on the four arms of the specimen. For the specimen, two steps of thickness reduction are adapted in the central region. The first thickness reduction is a circle with an arc profile in the sheet thickness. The second thickness reduction is a square with edges parallel to the arms. Four slits are added on arms to reduce their transverse rigidity and eliminate geometric constraints.

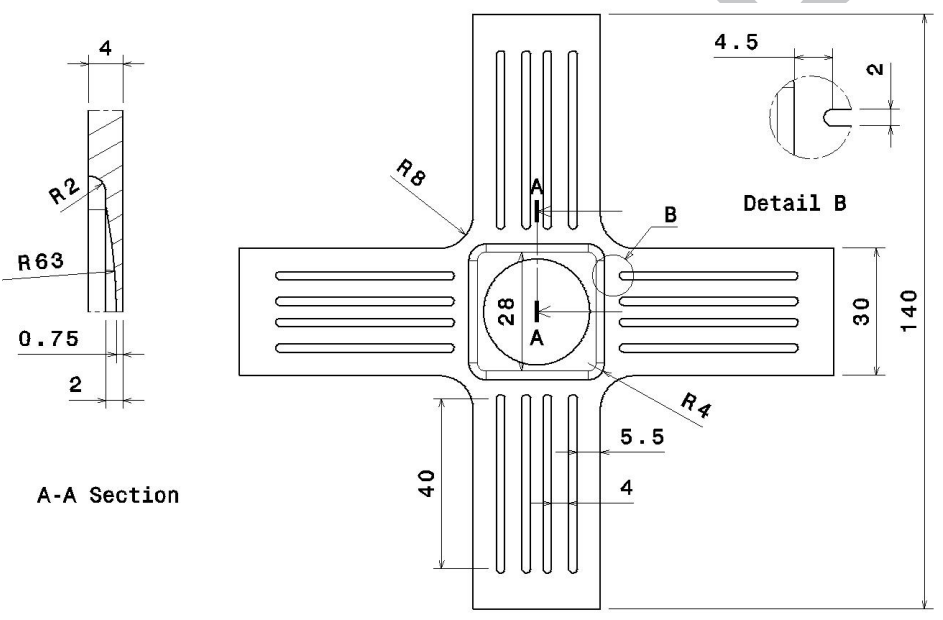

Figure 2: Geometry of specimen

All the cruciform specimens are made from AA5086H111 sheet blanks with a $4 \mathrm{~mm}$ initial thickness. The central region of the specimen is manufactured by using a digital numerical turning-lathe, with a precision of 0.02 $\mathrm{mm}$ for the central thickness. The effect of the machining process on the determination of the limit strains was evaluated and it was shown that this effect was included in the intrinsic scattering resulting from the determination of unstable behaviours like necking or rupture. The experimental device is a servo-hydraulic testing machine provided with four independent dynamic actuators allowing biaxial tensile tests on cruciform specimens following two perpendicular axes. Different strain paths are obtained (from uniaxial to equibiaxial stretching), a velocity of $1 \mathrm{~mm} / \mathrm{s}$ is fixed for one axis (rolling direction of the sheet), and the velocity varies from free to $1 \mathrm{~mm} / \mathrm{s}$ for the 
other one.

\subsection{Method to detect the onset of fracture}

Classically, the forming limit strains at fracture are obtained by the circlegrid analysis. A grid of circles (usually a diameter between 2 and $5 \mathrm{~mm}$ ) is imprinted on the surface of the blanks before forming. The limit major and minor strains are calculated by the ellipses near or at the fracture site, after the test. Such method suffers from sensitivity to the initial size of the circles in the neighborhood of the crack and the evolution of strain field is not followed during the test. The Digital Image Correlation (DIC) is used here to evaluate the strain components at the surface sample from the beginning of the test to fracture. A fast camera associated with a macro lens is used to capture the consecutive images and an acquisition of 250 images/s is adopted. The commercial digital imaging program CORRELA2006 is employed to evaluate the surface strains of the specimen.

A time-dependent method based on the evolution of major strain and on the observation of the macroscopic image of specimen surface is proposed to identify the onset of fracture and the forming limit strains at fracture. The evolution of major strain is followed in the crack zone, located in the central zone $(2.4 \times 2.4 \mathrm{~mm}$ size $)$ of the specimen (Figure 3$)$. The evolution of major strain in the central zone under equibiaxial stretching is plotted in Figure 4. The strain versus time curve is typical of Portevin-Le-Chatelier (PLC) effects, with steps on the strain evolution, this phenomenon is well known for 5000 series aluminium alloys. In the central zone, the level of major strain increases with time and an abrupt change can be observed at last. As shown in Figure 5, a macroscopic crack appears when the abrupt change of major strain happens. The appearance of macroscopic crack is accompanied with an abrupt increase of major strain in a very short time (0.004s). More strain paths are considered for the proposed method to identify the onset of fracture. Same phenomena are observed in Figure 6 under plane-strain tension and in Figure 7 under uniaxial tension. In the present work, the major and minor strains of the central zone at the time just before onset of macroscopic fracture are defined as the forming limit strains at fracture.

\subsection{Forming limit curve at fracture}

The strain path at the central point of the cruciform specimen is directly linked to the velocity ratio of actuators. They remotely act on the central zone of the specimen and strain ratio in the centre is not exactly the 


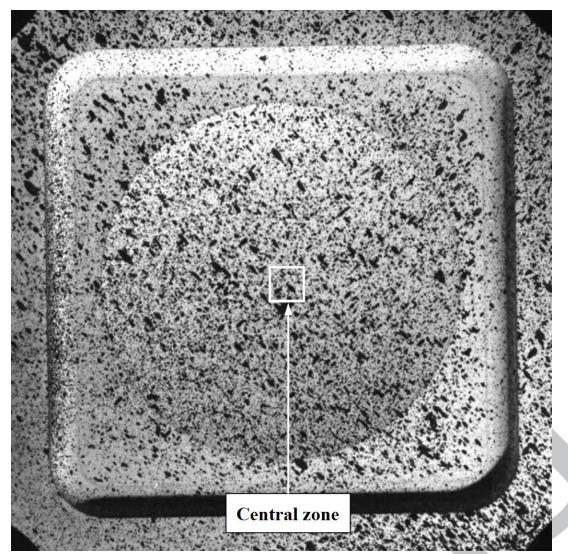

Figure 3: The central zone used for measuring the evolution of major strain

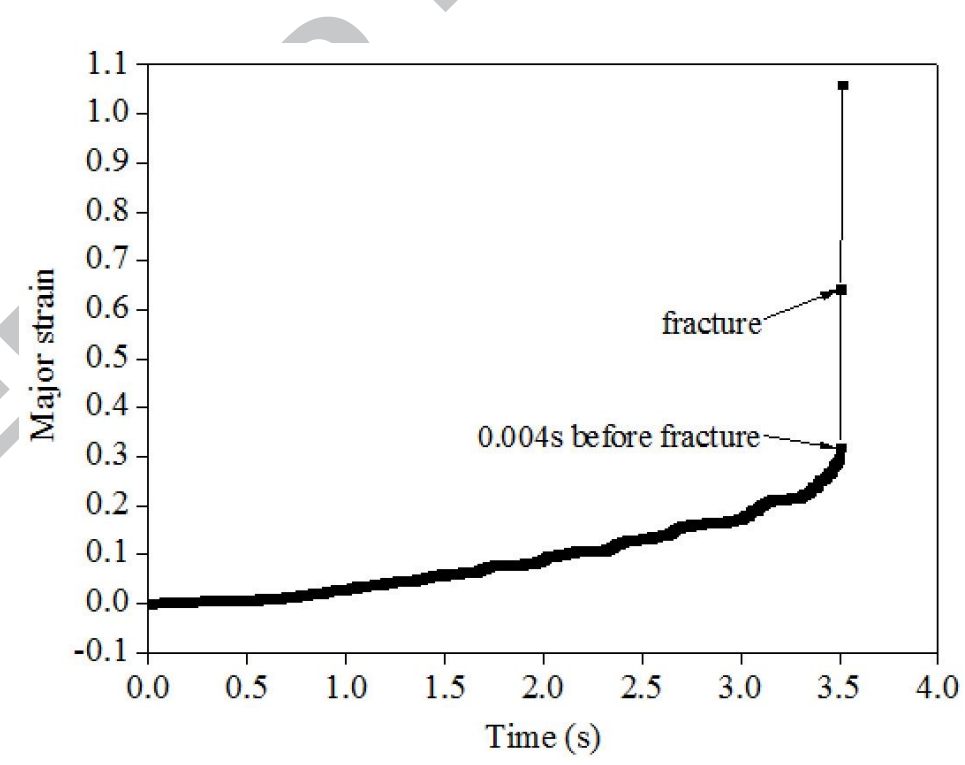

Figure 4: Evolution of major strains under equibiaxial stretching 


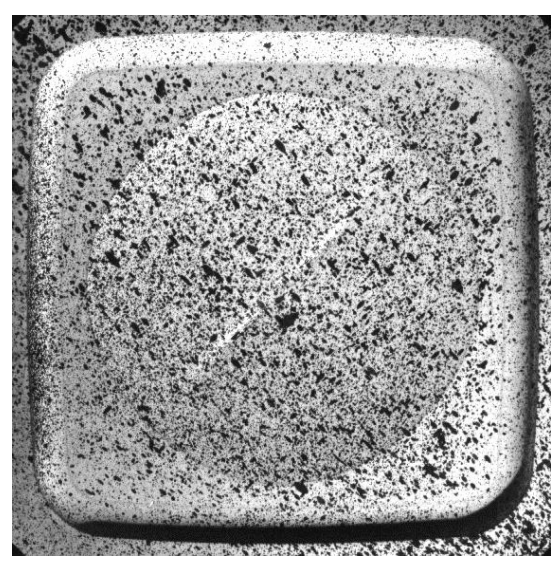

(a) $0.004 \mathrm{~s}$ before fracture

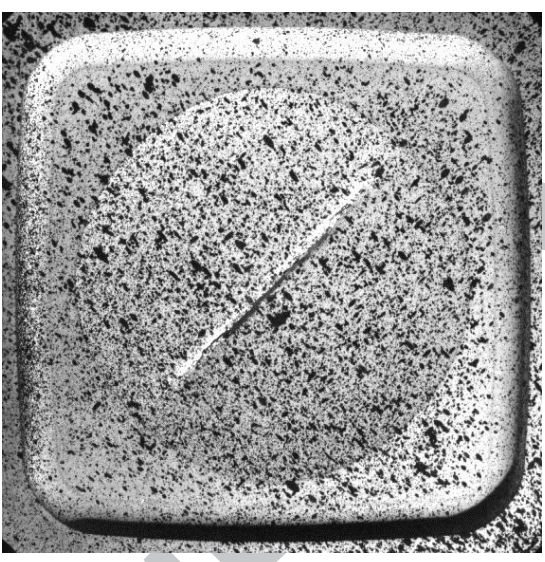

(b) fracture

Figure 5: DIC figures of the specimen under equibiaxial stretching

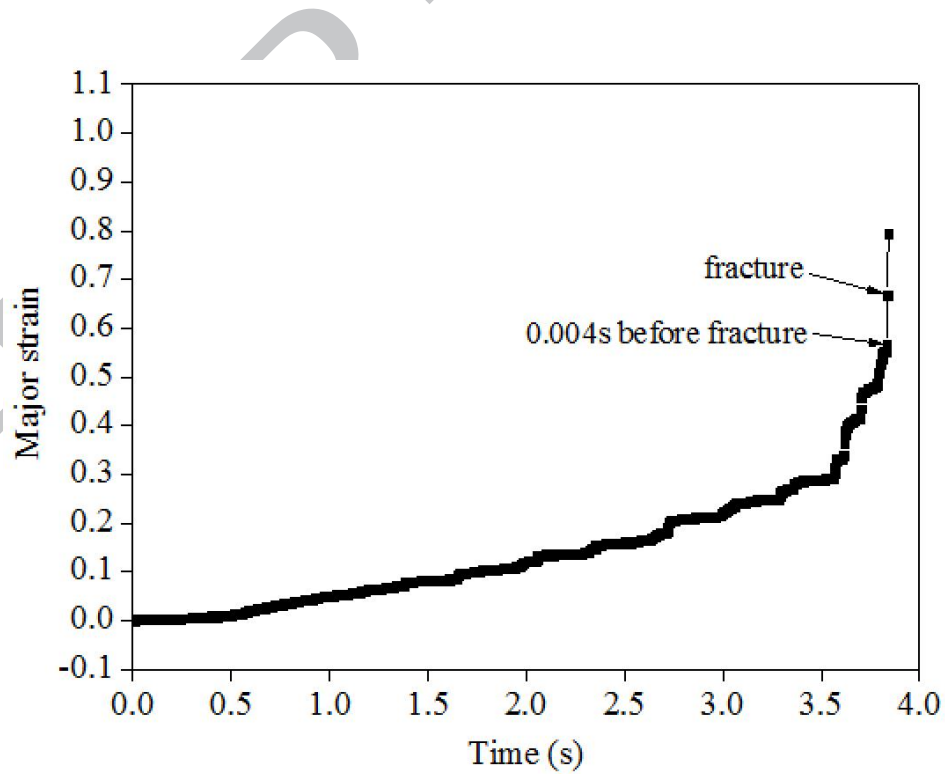

Figure 6: Evolution of major strains under plane-strain tension 


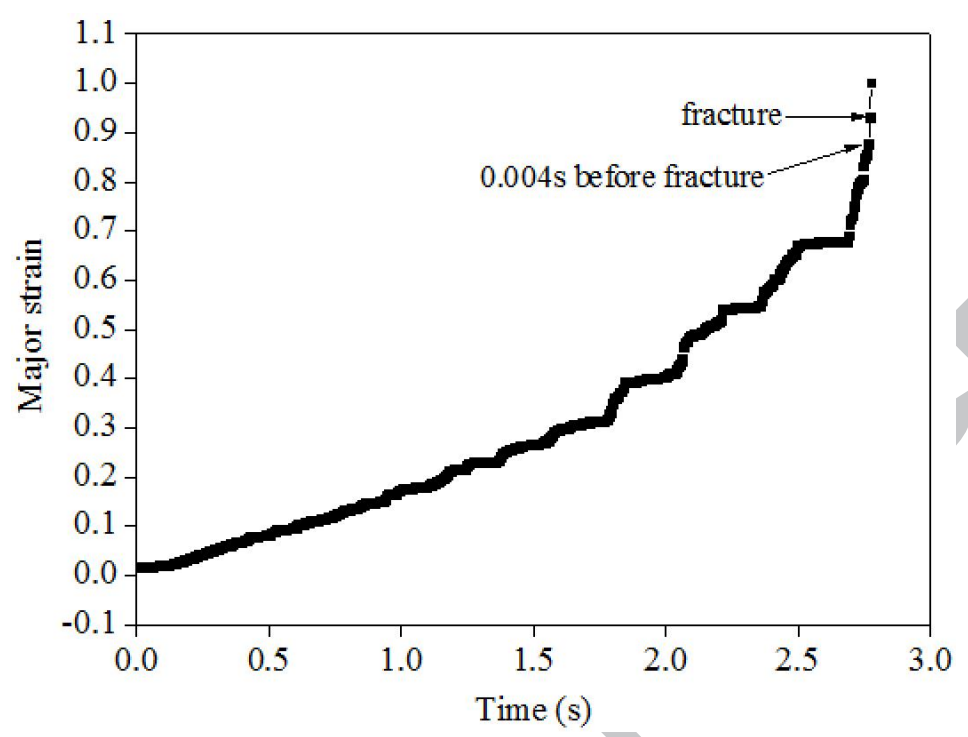

Figure 7: Evolution of major strains under uniaxial tension

same as the one for imposed velocities. The small difference is linked to the heterogeneous shape of the specimen and to the elastoplastic behaviour of material (mainly anisotropy). As shown in Figure 8, experiments are carried out under various strain paths from uniaxial to equibiaxial stretching. Dashed lines indicate the followed strain paths under equibiaxial, plane-strain and uniaxial tension, respectively. All the strain paths are quasi-linear for a constant speed ratio. A velocity of $1 \mathrm{~mm} / \mathrm{s}$ is fixed for the rolling direction of the sheet and the velocity in the transverse direction is respectively set to free, $0.05 \mathrm{~mm} / \mathrm{s}, 0.25 \mathrm{~mm} / \mathrm{s}, 0.5 \mathrm{~mm} / \mathrm{s}, 0.75 \mathrm{~mm} / \mathrm{s}$ and $1 \mathrm{~mm} / \mathrm{s}$. The solid markers represent the forming limit strains at fracture identified by the above-mentioned time-dependent method, under the different strain paths.

Due to the good ductility of AA5086 [1] and as described by the Fracture Forming Limit line concept (FFL), the forming limit strains at fracture can be fitted by a straight line falling from left to right with the least-squares method (Eq. 2). Based on the experimental results (Figure 8), $k=-1.13$ and $A=0.58$ (R-squared value of 0.89 ).

$$
\varepsilon_{\text {major }}=k \varepsilon_{\text {minor }}+A
$$

For comparison, Figure 9 shows limit strains at necking and at fracture for the same specimens. Forming limit strains at necking have been deter- 


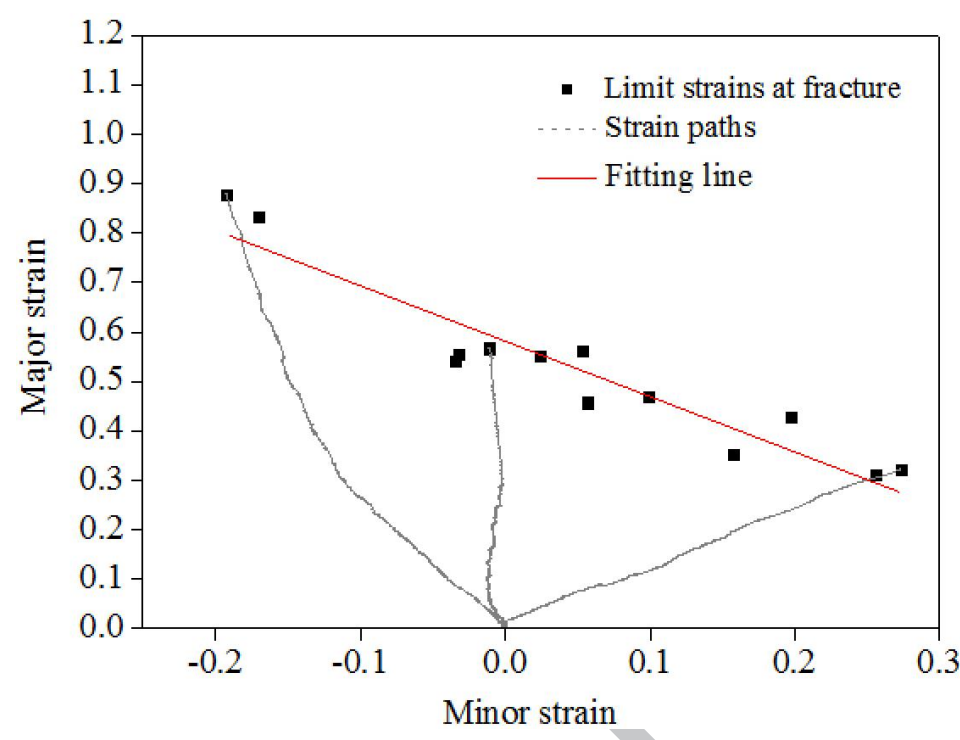

Figure 8: Limit strains at fracture under different strain paths

mined by fulfilling the standard requirements concerning the use of a positiondependent method [11]. As expected, limit strains at fracture are higher than the limit strains at necking, especially for plane-strain conditions. For uniaxial and equibiaxial stretching, necking is rapidly followed by a crack onset. One can notice the high level of major strain at necking for uniaxial tension (between 60 and 70\%). This point has been widely discussed in [9]. Due to the specimen geometry, the mechanisms of the necking onset are different in the in-plane biaxial test and in the conventional Marciniak test. This difference can explain the improvement of formability observed with the cruciform shape. For the cruciform shape the forming limit criterion detects the onset of localized necking whereas for the Marciniak test it is activated during the diffuse necking stage, prior to localized necking. Moreover, in narrow specimens of the Marciniak test (not really representative of the complex shape of industrial parts under uniaxial tension), the appearance of diffuse necking probably accelerates the onset of localized necking. For the cruciform shape, the in-plane strain evolutions are relatively stable before localized necking. 


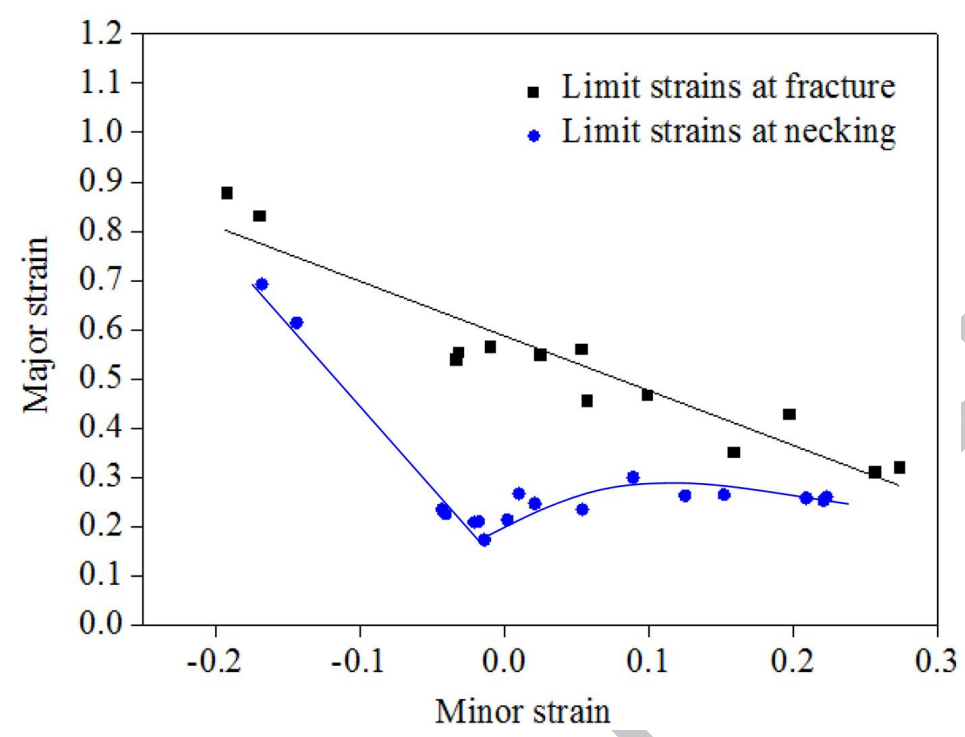

Figure 9: Limit strains at necking and at fracture under different strain paths

\section{Prediction of forming limit curve at fracture}

\subsection{Numerical model}

As shown in Figure 10, a predictive model for forming limit strains at fracture has been built by modeling the cruciform specimen shape with the finite element (FE) method. FE simulations have been carried out with the commercial software ABAQUS (implicit solver). Only one-quarter of the specimen is analyzed for considering the symmetry of the specimen geometry. Tetrahedral elements are used (more than 130000 elements) and a refined mesh (average mesh size of $0.25 \mathrm{~mm}$ ) is assumed where fracture may appear. Different displacement ratios are imposed on the two orthogonal directions to reproduce the experimental strain paths.

To describe the material elasticity, a Young's modulus of $73022 \mathrm{MPa}$ and a Poisson's ratio of 0.33 are considered. Hill48 yield criterion for plane stress condition is adopted and the equivalent stress $\bar{\sigma}$ is expressed by a quadratic function of the following type:

$$
\bar{\sigma}^{2}=(G+H) \sigma_{x x}^{2}+(F+H) \sigma_{y y}^{2}-2 H \sigma_{x x} \sigma_{y y}+2 N \sigma_{x y}^{2}
$$

The parameters of Hill48 yield criterion for AA5086 were identified by present authors [26]. As shown in Table 1, three anisotropic coefficients 


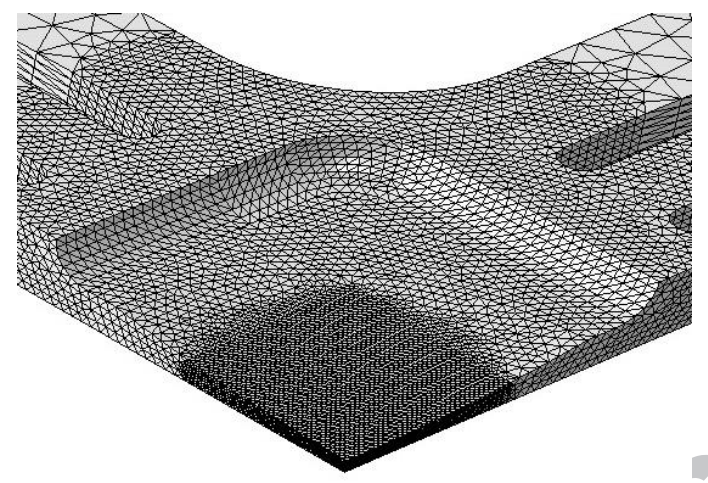

Figure 10: 3D Mesh of the cruciform specimen

$\left(r_{0}, r_{45}\right.$ and $\left.r_{90}\right)$ were obtained by uniaxial tensile tests carried out along the rolling, diagonal and transverse directions. Constants F, G, H, and $\mathrm{N}$ for plane stress conditions are calculated from the three plastic anisotropic coefficients.

Table 1: Lankford's coefficient and Hill48 yield parameters [26]

\begin{tabular}{ccccccccc}
\hline$r_{0}$ & $r_{45}$ & $r_{90}$ & $\mathrm{~F}$ & $\mathrm{G}$ & $\mathrm{H}$ & $\mathrm{L}$ & $\mathrm{M}$ & $\mathrm{N}$ \\
\hline 0.49 & 0.62 & 0.52 & 0.632 & 0.671 & 0.329 & 1.500 & 1.500 & 1.460 \\
\hline
\end{tabular}

A modified form of Voce's hardening law [27] has been adopted to limit the saturating behaviour of classical Voce's formulation:

$$
\bar{\sigma}=\sigma_{0}+K \sqrt{1-\exp \left(-n \bar{\varepsilon}_{p}\right)}
$$

Using a dedicated cruciform specimen, an experimental biaxial flow stress curve for AA5086 up to $30 \%$ of the equivalent plastic strain has been obtained by the authors [27]. The parameters $\sigma_{0}, K$ and $n$ were identified (Table 2) for Hill48 yield criterion thanks to an inverse procedure.

Table 2: Identified parameters of hardening law [27]

\begin{tabular}{ccc}
\hline$\sigma_{0}(M P a)$ & $\mathrm{K}(\mathrm{MPa})$ & $\mathrm{n}$ \\
\hline 153.62 & 249.75 & 3.392 \\
\hline
\end{tabular}




\subsection{Ductile fracture criteria}

In order to predict limit strains at rupture with the above numerical model, three existing ductile fracture criteria from literature are selected: Cockroft and Latham, Brozzo and Ayada. Various stress tensor invariants, such as the maximum principal stress $\sigma_{\max }$, the equivalent stress $\bar{\sigma}$ and the hydrostatic stress $\sigma_{h}$ are involved in these criteria. For each criterion, only one parameter needs to be identified. It is assumed that fracture would occur when the parameter $C_{i}(\mathrm{i}=1,2$, and 3$)$ reaches a critical damage value.

The classical Cockroft and Latham criterion [28] is not based on a micro mechanical model of fracture but depends on the critical value at fracture upon the level of maximum principal stress (Eq. 5).

$$
\int_{0}^{\bar{\varepsilon}_{f}} \frac{\sigma_{\max }}{\bar{\sigma}} d \bar{\varepsilon}_{p}=C_{1}
$$

The Cockroft and Latham criterion was modified by Brozzo et al. [29] and the effect of hydrostatic stress in an explicit form was introduced as follows:

$$
\int_{0}^{\bar{\varepsilon}_{f}} \frac{2}{3}\left(1-\frac{\sigma_{h}}{\sigma_{\max }}\right)^{-1} d \bar{\varepsilon}_{p}=C_{2}
$$

Finally, the criterion from Ayada et al. [30] is also considered (Eq. 7). The fundamentals of this criterion are based on the work of McClintock [31], in which a relation between the inter-hole spacing, the diameter of the hole (particle/inclusion) and stress triaxiality at the onset of fracture under tension loading is established. This criterion includes the effect of hydrostatic stress and has proved its efficiency for some forming operations [22].

$$
\int_{0}^{\bar{\varepsilon}_{f}} \frac{\sigma_{h}}{\bar{\sigma}} d \bar{\varepsilon}_{p}=C_{3}
$$

\subsection{Results}

The damage value $C_{i}$ of the three criteria can be calculated at each step of the finite element simulation. The numerical forming limit strains at fracture under the different strain paths are identified by the same critical damage value. All these forming limit strains will be used to produce a numerical FLCF. For the calibration of the critical damage value, the experimental forming limit strains under uniaxial, plane-strain and equibiaxial stretching are respectively considered and compared. 
Figure 11 shows the FLCFs calculated with the three criteria when the critical damage value is calibrated with experimental forming limit strains under equibiaxial stretching. The FLCFs from Cockroft and Latham criterion and Ayada criterion are approximately described by a linear shape, while the FLCF identified by Brozzo criterion shows a curve profile. A good correlation is found with the Ayada criterion whereas Cockroft and Latham criterion and Brozzo criterion respectively underestimates and overestimates limit strains. The FLCFs identified by the three criteria for a calibration under plane-strain and uniaxial tension are shown in Figure 12 and Figure 13, respectively. The critical damage values of the criteria under the various strain paths are shown in Table 3. For the right hand side of the forming limit diagram (positive minor strains), the correlation between experimental limit strains and the ones from Ayada criterion is excellent, the calibration of $C_{3}$ gives the same results for plane-strain or equibiaxial stretching. For the three criteria, the prediction is reasonable when the calibration of critical damage value is done under plane-strain tension (Figure 12). But when the calibration is made with experimental limit strains under uniaxial tension, which is usually the case when only uniaxial experiments are available, the predictions under the expansion mode are very imprecise and strongly overestimated for the three criteria. Globally, for this aluminium alloy, Ayada criterion gives the best predictions and it is recommended to calibrate the critical damage values under plane strain condition.

Table 3: The critical damage values of the criteria under various strain paths

\begin{tabular}{cccc}
\hline Loading state & $C_{1}$ & $C_{2}$ & $C_{3}$ \\
\hline Equibiaxial & 0.64 & 1.20 & 0.46 \\
\hline Plane-strain & 0.80 & 0.93 & 0.43 \\
\hline Uniaxial & 1.18 & 1.29 & 0.64 \\
\hline
\end{tabular}

In the present work, the classical Hill48 yield criterion was used from a practical point of view. As it was shown in [26], the Hill48 gives a reasonable description of AA5086 anisotropy but the use of a complex anisotropic yield criterion, like the one from Bron and Besson, can improve this description (mainly under equibiaxial conditions). In order to evaluate the impact of the choice of the yield criterion, we propose to compare the prediction of FLCFs by using the Hill48 criterion and the isotropic Mises criterion. The best 


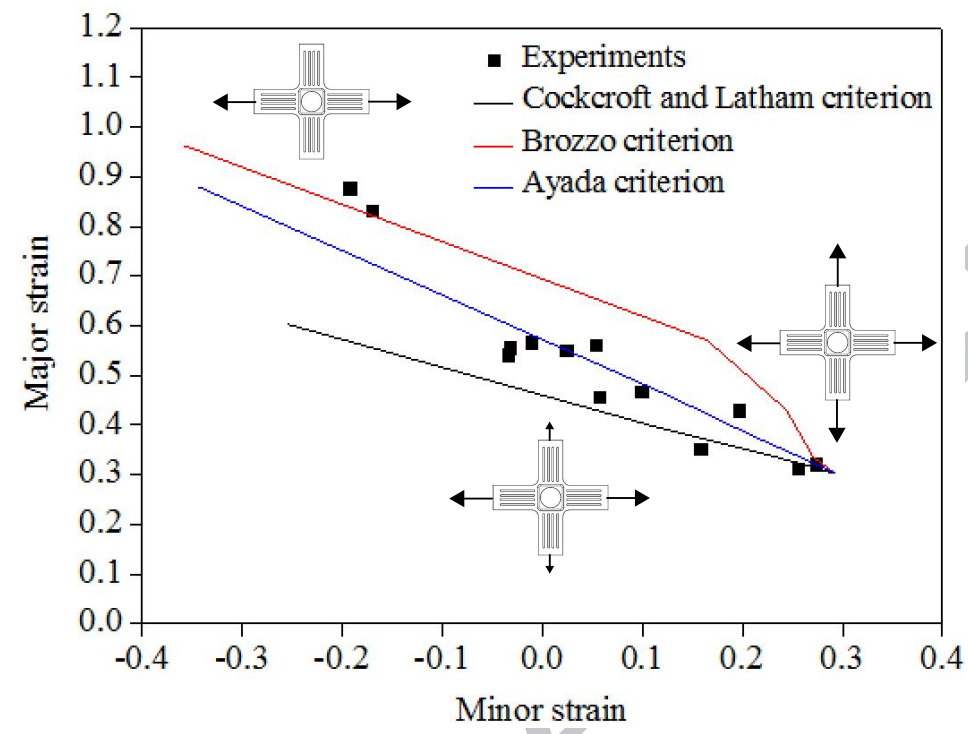

Figure 11: FLCFs identified by the three criteria (calibration under equibiaxial stretching)

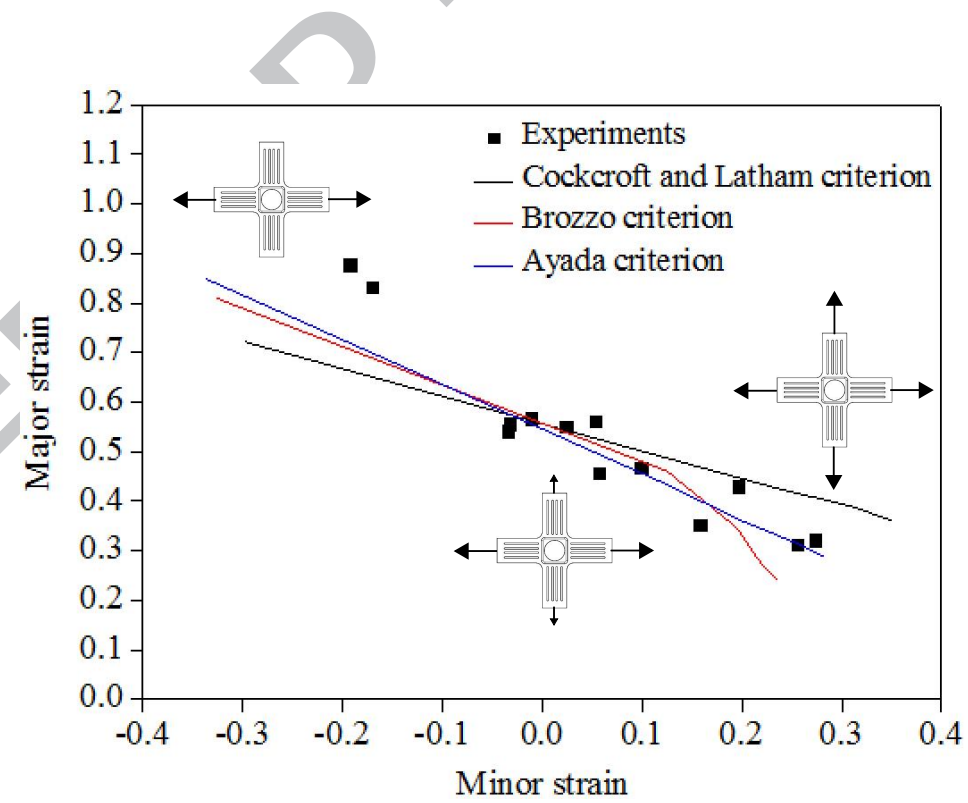

Figure 12: FLCFs identified by the three criteria (calibration under plane-strain tension) 


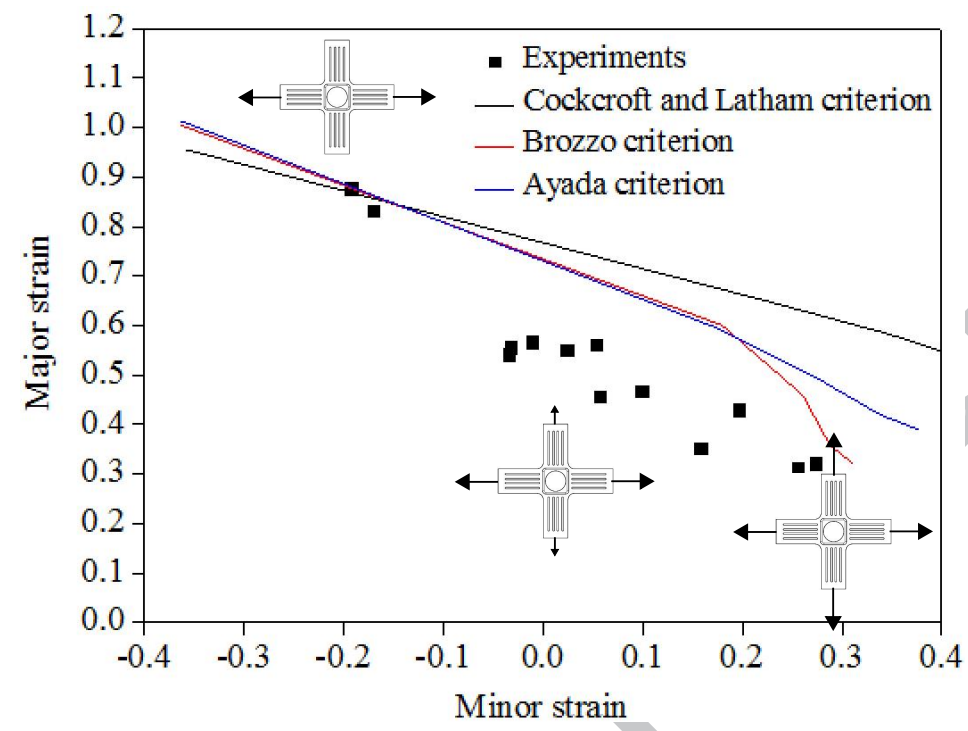

Figure 13: FLCFs identified by the three criteria (calibration under uniaxial tension)

fracture criterion (Ayada) is chosen for comparison and the recommended calibration procedure was applied (under plane strain condition) with the isotropic Mises yield criterion. The effect on the critical damage value C3 is moderate (0.5 instead of 0.43 ) and Figure 14 shows that the shapes of the FLCFs obtained with the two yield criteria are very close. 


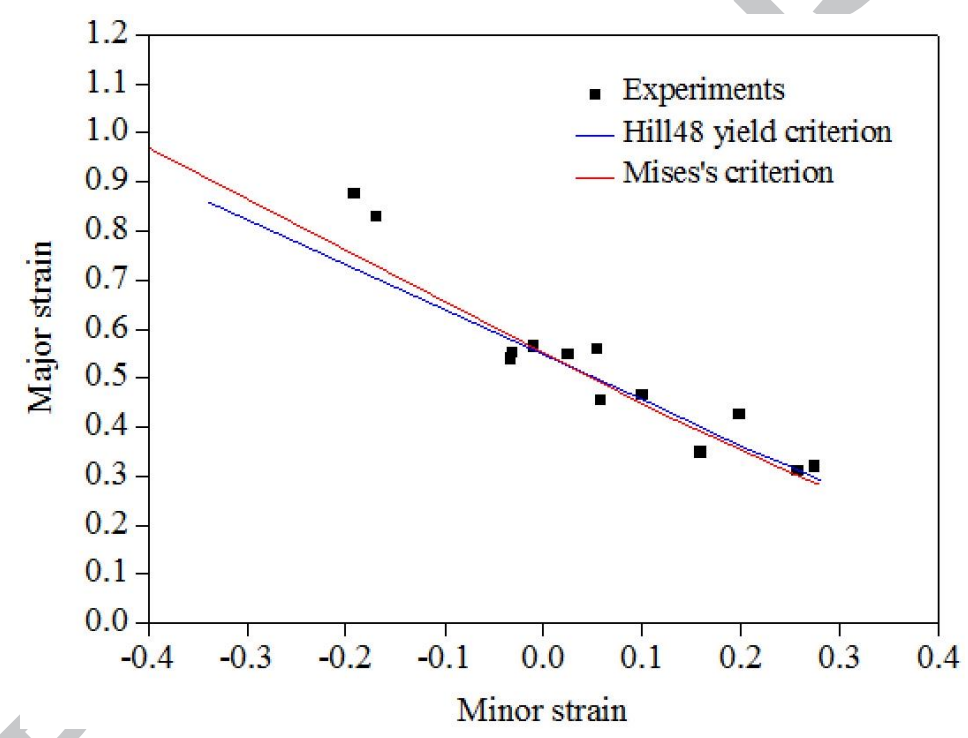

Figure 14: Effect of yield criterion on the prediction of FLCFs 


\section{Conclusions and perspectives}

In this work, the in-plane biaxial tensile test with a dedicated cruciform specimen has been used to investigate the fracture in sheet metal forming. The experimental results show that only one shape of specimen permits to reach strain paths from uniaxial to equibiaxial stretching, by piloting the velocity of actuators on the two perpendicular axes of the experimental device. For AA5086, the forming limit strains at fracture can be identified by a time-dependent method combining the evolution of major strain with the observation of the macroscopic crack at the specimen surface. In accordance with the Fracture Forming Limit line concept, the forming limit strains at fracture under the different strain paths can be fitted by a straight line.

The numerical predictions of FLCFs with three fracture criteria from literature can give very different results, depending on the experimental forming limits chosen to calibrate the critical damage value. The Ayada criterion gives the best result and is insensitive to the experimental limit strains used for calibration in the expansion mode.

Linear strain paths are considered in this study but complex loading paths are generally observed in actual forming processes. The presented procedure is really promising since the control of the strain path in the fracture zone is made by the displacements of the four independent actuators of the device. As a result, non-linear strain paths, without unloading, can be studied and the pertinency of fracture criteria can be evaluated for complex loadings. 


\section{References}

[1] P.A.F. Martins, N. Bay, A.E. Tekkaya, and A.G. Atkins. Characterization of fracture loci in metal forming. International Journal of Mechanical Sciences, 83:112-123, 2014.

[2] S. Bruschi, T. Altan, D. Banabic, P.F. Bariani, A. Brosius, J. Cao, A. Ghiotti, M. Khraisheh, M. Merklein, and AE. Tekkaya. Testing and modelling of material behaviour and formability in sheet metal forming. CIRP Annals-Manufacturing Technology, 63(2):727-749, 2014.

[3] H. Takuda, K. Mori, N. Takakura, and K. Yamaguchi. Finite element analysis of limit strains in biaxial stretching of sheet metals allowing for ductile fracture. International Journal of Mechanical Sciences, 42(4):785-798, 2000.

[4] H.N. Han and K.H. Kim. A ductile fracture criterion in sheet metal forming process. Journal of Materials Processing Technology, 142(1):231-238, 2003.

[5] M.B. Silva, M. Skjoedt, A.G. Atkins, N. Bay, and P.A.F. Martins. Single-point incremental forming and formability-failure diagrams. The Journal of Strain Analysis for Engineering Design, 43(1):15-35, 2008.

[6] M.B. Silva, P.S. Nielsen, N. Bay, and P.A.F. Martins. Failure mechanisms in single-point incremental forming of metals. The International Journal of Advanced Manufacturing Technology, 56(9):893-903, 2011.

[7] K. Isik, M.B. Silva, A.E Tekkaya, and P.A.F. Martins. Formability limits by fracture in sheet metal forming. Journal of Materials Processing Technology, 214(8):1557-1565, 2014.

[8] P.A.F. Martins, L. Montanari, V.A. Cristino, and M.B. Silva. Formability and simulative tests in modern sheet metal forming education. In Modern Mechanical Engineering, pages 411-447. Springer, 2014.

[9] L. Leotoing, D. Guines, I. Zidane, and E. Ragneau. Cruciform shape benefits for experimental and numerical evaluation of sheet metal formability. Journal of Materials Processing Technology, 213(6):856-863, 2013. 
[10] I. Zidane, D. Guines, L. Leotoing, and E. Ragneau. Development of an in-plane biaxial test for forming limit curve (flc) characterization of metallic sheets. Measurement Science and Technology, 21(5):055701(11pp), 2010.

[11] L. Leotoing and D. Guines. Investigations of the effect of strain path changes on forming limit curves using an in-plane biaxial tensile test. International Journal of Mechanical Sciences, 99:21-28, 2015.

[12] B.P.P.A. Gouveia, J.M.C. Rodrigues, and P.A.F. Martins. Ductile fracture in metalworking: experimental and theoretical research. Journal of Materials Processing Technology, 101(1):52-63, 2000.

[13] J. Besson, D. Steglich, and W. Brocks. Modeling of plane strain ductile rupture. International Journal of Plasticity, 19:1517-1541, 2003.

[14] F. Ozturk and D. Lee. Analysis of forming limits using ductile fracture criteria. Journal of Materials Processing Technology, 147(3):397-404, 2004 .

[15] H. Li, M.W. Fu, J. Lu, and H. Yang. Ductile fracture: experiments and computations. International Journal of Plasticity, 27:147-180, 2011.

[16] V. Tvergaard and A. Needleman. Analysis of the cup-cone fracture in a round tensile bar. Acta Metallurgica, 32:157-169, 1984.

[17] J. Lemaitre. A continuous damage mechanics model for ductile fracture. Journal of Engineering Materials and Technology, 107:83-89, 1985.

[18] Q.M. Li. Strain energy density failure criterion. International Journal of Solids and Structures, 38:6997-7013, 2001.

[19] A.S. Khan and H.W. Liu. A new approach for ductile fracture prediction on al 2024-t351 alloy. International Journal of Plasticity, 35:1-12, 2012.

[20] S.E. Clift, P. Hartley, C.E.N. Sturgess, and G.W. Rowe. Fracture prediction in plastic deformation processes. International Journal of $\mathrm{Me}$ chanical Sciences, 32(1):1-17, 1990.

[21] H. Takuda, K. Mori, and N. Hatta. The application of some criteria for ductile fracture to the prediction of the forming limit of sheet metals. Journal of materials processing technology, 95(1):116-121, 1999. 
[22] A. Mishra and S. Thuillier. Investigation of the rupture in tension and bending of dp980 steel sheet. International Journal of Mechanical Sciences, 84:171-181, 2014.

[23] M. Jain, J. Allin, and D.J. Lloyd. Fracture limit prediction using ductile fracture criteria for forming of an automotive aluminum sheet. International Journal of Mechanical Sciences, 41(10):1273-1288, 1999

[24] International Standard ISO16842. Metallic materials-sheet and stripbiaxial tensile testing method using a cruciform test piece, 2014.

[25] T. Kuwabara, S. Ikeda, and K. Kuroda. Measurement and analysis of differential work hardening in cold-rolled steel sheet under biaxial tension. Journal of Materials Processing Technology, 80-81:517-523, 1998.

[26] S. Zhang, L. Leotoing, D. Guines, S. Thuillier, and S.L. Zang. Calibration of anisotropic yield criterion with conventional tests or biaxial test. International Journal of Mechanical Sciences, 85:142-151, 2014.

[27] W. Liu, D. Guines, L. Leotoing, and E. Ragneau. Identification of sheet metal hardening for large strains with an in-plane biaxial tensile test and a dedicated cross specimen. International Journal of Mechanical Sciences, 101:387-398, 2015.

[28] M.G. Cockroft and D.G. Latham. Ductility and the workability of metals. Journal of the Institute of Metals, 96:33-39, 1968.

[29] P. Brozzo, B. Deluca, and R. Rendina. A new method for the prediction of formability in metal sheets. In Proceedings of the Seventh Biennial Conference of the IDDRG, 1972.

[30] M. Ayada, T. Higashino, and K. Mori. Central bursting in extrusion of inhomogeneous materials. Advanced Technology of Plasticity, 1:553-558, 1987.

[31] F.A. McClintock. A criterion for ductile fracture by the growth of holes. Journal of Applied Mechanics, 35:363-371, 1968. 
- An in-plane biaxial tensile test is proposed to determine limit strains at fracture

- Strain path is controlled by displacements in two directions of cruciform specimen

- Comparison of numerical forming limit strains with three ductile fracture criteria

- Critical damage values identified by experimental results under various strain paths 
Nomenclature

- FLCN : Forming Limit Curve at Necking

- FLCF : Forming Limit Curve at Fracture

- SPIF : Single Point Incremental Forming

- DIC : Digital Image Correlation 